\title{
Rapid increase of overweight and obesity among primary school-aged children in the Caribbean; high initial BMI is the most significant predictor
}

Walaa A. Mumena ${ }^{1 *}$ (D) Isabella Francis-Granderson ${ }^{2}$, Leroy E. Phillip ${ }^{3}$ and Katherine Gray-Donald ${ }^{4}$

\begin{abstract}
Background: To examine predictors of increasing overweight among children in two developing countries.

Methods: Primary school children (6-10 y at baseline, $n=336)$ and their caregivers.

Longitudinal data were collected in 2012, with follow-up 18 months later. Data on children's height, weight and dietary intake were collected within 8 primary public schools in Trinidad and 7 schools in St. Kitts. Caregivers' demographic and anthropometric data were also collected.

Results: At baseline, children's age and sex and caregivers' BMI, age, and marital status and reported dietary intake were similar across all weight groups. The incidence of overweight and obesity among children was $8.8 \%$ and $8.1 \%$, respectively. Dietary intake at baseline was not related to becoming overweight or obese. Similarly there were no differences in reported intake among children who became overweight or obese except that they consumed fewer fruits $(0.54 \pm 0.92$ vs. $0.98 \pm 1.66, p=0.017)$. Misreporting of energy intake was higher among overweight/obese children as compared to those who were not overweight/obese ( $27 \%$ vs. $17 \%, p=0.047$ ). The baseline predictors of increasing $\mathrm{BMI}$ (adjusted) of the children were older age, higher baseline BMI z-score and higher height-for-age (HFA) z-score; caregiver BMl, children's energy intake (with adjustment for misreporting) did not predict changes in children's BMI.

Conclusions: The increasing prevalence of overweight/obesity among children is a serious problem in the Caribbean. Heavier children are at elevated risk of continued rapid increase in their weight status, pointing to the need for early intervention.
\end{abstract}

Keywords: Obesity, Incidence, Predictors, Caribbean children, Misreporting

\section{Background}

The prevalence of obesity has increased over the last few decades and has now become a worldwide public health problem [1]. It is becoming more prevalent among all age groups including children in developing countries [2]. Childhood obesity is a matter of concern because obese children are at higher risk of becoming obese adults [3-5], and are at increased risk of suffering from noncommunicable chronic diseases, such as diabetes and coronary heart disease, later in life [6]. Moreover, obese

\footnotetext{
* Correspondence: wmumena@taibahu.edu.sa

${ }^{1}$ Clinical Nutrition Department, College of Applied Medical Sciences, Taibah University, Al-Madinah, Saudi Arabia

Full list of author information is available at the end of the article
}

children already have a higher prevalence of insulin resistance $[7,8]$ and elevated blood pressure [9].

Predictors of overweight and obesity among children in the developed world are well investigated, but this is not the case in developing countries. Energy intake, as well as certain dietary patterns [10-13], low levels of physical activity [14, 15], high baseline BMI [15] and parental BMI [15-17] are well-known predictors of weight gain among populations in developed countries. The "nutrition transition", defined as the shift to more "Westernized" dietary practices and increasingly sedentary lifestyles, has been linked to the increased prevalence of childhood overweight and obesity in developing countries $[18,19]$. In the Caribbean, the prevalence of overweight and obesity 
among children is steadily increasing. Between 1990 and 1999, childhood obesity in Dominica increased from 6.0\% to $9.7 \%$, while in St. Kitts the prevalence has increased from $7.1 \%$ to $10.6 \%$ [20]. A recent study in Barbados, using identical reference standards, reveal that between 1981 and 2010 the prevalence of overweight and obesity among children aged $8-11$ years $(n=580)$ increased from $8.5 \%$ to $32.5 \%$ [21].

The purpose of this study was to determine the incidence of becoming overweight or obese over a period of 18 months for children aged 6 to 10 years living in two Caribbean countries, and to examine dietary and other predictors of increasing adiposity for these children.

\section{Methods}

This study was part of a broader multidisciplinary project dealing with food and nutrition security in the Caribbean Community (CARICOM), with a focus on improving nutritional outcomes of children in the region; details of the broader project work reported elsewhere [22]. Ethical approvals were obtained from the McGill Research Ethics Committee; the Ministry of Education in St. Kitts and Nevis; the Ministry of Health St. Kitts and Nevis; the Ministry of Food Production, Land and Marine Affairs in Trinidad and Tobaggo; the Ministry of Health, and the Ministry of Education, Republic of Trinidad and Tobago, Research and Publication Unit.

Data for this study were collected between January and July 2012 in a first phase and follow-up data were collected between September 2013 and April 2014. Children aged 6-10 years and their caregivers were recruited from eight schools in Trinidad and Tobago and seven schools in St. Kitts and Nevis. The population in Trinidad and Tobago is a mix of Afro-Caribbean and Indo-Caribbean peoples, while in St. Kitts and Nevis the population is solely Afro-Caribbean. In Trinidad, schools were selected from those with a high proportion of children who received a government-provided school lunch and included both rural and urban schools. Schools in St. Kitts, where all children are offered a free lunch, were selected from rural areas near the capital of Basseterre. A letter to parents requesting the participation of caregiver and their child was provided to the household and only those children with signed parental consent were enrolled. For families with more than one child in the desired age range, one child was randomly chosen. Interviews were conducted at home and trained interviewers collected a single 24-h dietary recall for each child, undertaken with the child and caregiver together as recommended [23]. Demographic data collected included caregiver's age, sex, marital status, education and household size; measured height and weight of the caregiver were recorded during the home interview, and children's height and weight were measured at school.
Height was measured as "standing height" using a stadiometer, and body weight was measured using a digital floor scale. Weight of children was measured with no shoes, light clothing and empty pockets. BMI z-score following the World Health Organization (WHO) reference [24] was used to classify children's weight status. Change in children's BMI was calculated as suggested by Cole et al. [25] to avoid the ceiling effect of high percentiles and modeled z-scores. These were calculated by subtracting the sex-age-specific median BMI using the WHO reference from the measured BMI from baseline and follow-up measures. The median BMI for a child of 6 years is 15.3 for both sexes and for 12 year olds it is 18.0 for girls and 17.5 for boys. The change in median BMI over 18 months is very small from 6 to 7.5 years (0.2-0.3) and from 11 to 12.5 it is higher 0.8 for girls and 0.6 for boys.

To assess children's growth, which was a concern in the Caribbean region, height-for-age z-score (HFA zscore) was calculated using the WHO reference at each time point [26]. As an additional outcome measure to the adjusted change in BMI, a child was considered an incident case of overweight or obesity when a healthy weight child became overweight or obese, and when an overweight child became obese.

One 24-h dietary recall was conducted at baseline by locally trained interviewers. Caregivers and their children were interviewed at home and they were asked to provide details on the types and amounts of foods that were consumed by the child on the previous day (including vitamin and mineral supplements). Home interviews were done on different days of the week including weekends and holidays providing a sample of higher between-person variation of food intake. Data for a number of children were collected the day after a nonschool day and holidays. Portion models (Santé Quebec, Montreal, Canada) were used to help in the estimation of amounts consumed in milliliters; values for each food item were then converted to grams for data entry. CANDAT Nutrient Analysis Software (Godin London Incorporated, London, ON), was used for the nutrient analysis based on the Canadian Nutrition Files released in 2010 [27]. Where processed foods were locally produced, food labels or local recipes were added to the database. Foods groups were formed based on the Six Caribbean Food Groups (staples, legumes and nuts, foods from animals, fruits, vegetables, fats and oils) [28]. Green banana, plantain, breadfruit, corn, sweet potato and cassava are staples based on the Caribbean Food Groups, and serving sizes for these foods were calculated based on average carbohydrate content in one serving of grain. Portions of all other foods followed Canada's Food Guide portion sizes [29]. As the mean intake of a single day is a reliable measure of the intake of groups [30], 
this was used to compare the dietary intake of children who became overweight or obese versus children who remained at the same weight category. Food groupings were not used in regression models as the foods eaten by each child on 1 day is not representative of usual intake for a specific child for a specific food group.

To examine the extent of misreporting of energy intake and to adjust for it in the analysis, the ratio of reported energy intake (EI) to estimated total energy expenditure (TEE) was used to classify children to the appropriate misclassification group based on Goldberg cut-offs. Total energy expenditure was determined for each child using Torun equations [31]. A detailed explanation of this method is available elsewhere [32]. Children were classified as either "under-reporters", defined as having a ratio of EI:TEE $<0.76$, "plausible-reporters", having ratio of EI:TEE between 0.76 and 1.24, and "over-reporters", having ratio of $>1.24$ [32].

Descriptive data for the characteristics of children and their caregivers are presented as mean $\pm \mathrm{SD}$, and categorical variables are presented as percentages. WHO cut-off points were used to define caregivers weight status: thinness $<18.5\left(\mathrm{~kg} / \mathrm{m}^{2}\right)$, healthy weight $18.5-24.9$ $\left(\mathrm{kg} / \mathrm{m}^{2}\right)$, overweight $25-29.9\left(\mathrm{~kg} / \mathrm{m}^{2}\right)$, obesity $\geq 30(\mathrm{~kg} /$ $\mathrm{m}^{2}$ ) [33]. The WHO cut-off points for BMI z-score to define children's weight status are (severe thinness, $<-3$ (SD); thinness, < -2 (SD); overweight, >1 (SD); and obesity, $>2$ (SD)) [24]. The chi-square test was used to compare categorical data, while the t-test was used to compare mean for two groups and to compare means for 3 groups or more, ANOVA was used. Multiple regression analysis was performed to test for association between baseline BMI $\mathrm{z}$-score, baseline HFA z-score, age, energy intake, misreporting of energy intake (underreporters $=-1$, plausible-reporters $=0$, over-reporters $=$ 1 ), and caregiver BMI in relation to the change of children's BMI. All statistical tests were 2-tailed, and a significance level of $p<0.05$ was adopted. Correcting for multiple comparisons (dietary intake and weight category) was conducted using the Bonferroni method (dietary intake: $p<0.006$ and food groups: $p<0.01$ ). All statistical analyses were performed using $\mathrm{SAS}^{\bullet}$ software version 9.4 (2013, SAS Institute Inc., Cary, NC, USA).

\section{Results}

A total of 336 children and their caregivers were included in this study. We excluded 77 children $(15.6 \%)$ due to missing dietary data at baseline or follow up as appointments could not be conducted or caregivers' refusal to collect dietary data and 78 children (15.7\%) were excluded due to missing anthropometric data (moved to different school or were absent in the day of data collection). We also excluded 3 children $(0.60 \%)$ due to very low $<700$ $(\mathrm{kcal})$ or high $>3800(\mathrm{kcal})$ reported energy intake.
Demographic data for children and caregivers at baseline by weight categories of the children are shown in Table 1 . The caregivers were mostly female $(94 \%)$ and overweight or obese (mean BMI $40.1 \pm 9.08\left(\mathrm{~kg} / \mathrm{m}^{2}\right)$ ). Caregivers were similar in age, sex and marital status across all children's weight categories at baseline. There were no differences in children's age or sex among the all weight categories of the children.

A comparison of demographic variables, dietary intake and anthropometric measures at baseline and follow-up between countries indicated no differences were found. Results of children's weight status at baseline and at follow-up are shown in Table 2. At baseline, $22.0 \%$ of children were overweight or obese, while at follow-up $28.6 \%$ were overweight or obese. At follow-up, the percentage of children in the healthy weight category decreased by $6.8 \%$, while the percentage of overweight children remained the same and the percentage of obese children increased by $6.9 \%$. The incidence of healthy weight children becoming overweight was $8.8 \%$ and healthy weight and overweight children becoming obese was $8.1 \%$. A total of $15.1 \%(n=48)$ of children moved up to a higher weight category to become either overweight or obese, while only $1.58 \%(n=5)$ children moved down a weight category. The percentage of thin children (BMI $\mathrm{z}$-score $<-2$ (SD) remained constant.

Baseline dietary intakes of children were similar across the different baseline weight categories. The dietary intake of children who become overweight or obese was generally similar to the intake of children who did not move up a weight category (excluding thin children and children who were obese at baseline). The one exception was that children who moved up a weight category tended to consume less servings of fruit. There was no difference in reported energy intake for those who moved into a higher weight category vs. those who did not. See Table 3.

As it is important to measure the magnitude of gain in relation to baseline weight, we examined the change in BMI for each quartile of baseline BMI z-score. The average BMI change in the lowest BMI quartile at baseline was positive at 0.68 of a BMI unit adjusted for age and sex. The gain in the children in the highest quartile at baseline was considerably higher at 2.5 BMI units $(p<$ 0.001), (see Table 4). This increase in BMI units translates to an average weight gain of $12(\mathrm{~kg})$ (mean weight $32(\mathrm{~kg})$ at baseline and $44(\mathrm{~kg})$ at follow-up) for a child in the heaviest quartile; this can be compared to an average weight gain of $5(\mathrm{~kg})(25$ to $30(\mathrm{~kg})$ if the child gained weight following changes expected at the median BMI for age and sex.

In multiple regression analysis, higher baseline BMI zscores, higher baseline HFA z-scores and older age of children predicted increased change in BMI over the 
Table 1 Baseline demographic characteristics of children and their caregivers by children's baseline weight status in two Caribbean countries, St. Kitts and Nevis and Trinidad and Tobago $(n=336)$

\begin{tabular}{|c|c|c|c|c|}
\hline & $\begin{array}{l}\text { Thin } \\
(n=14)\end{array}$ & $\begin{array}{l}\text { Healthy weight } \\
(n=248)\end{array}$ & $\begin{array}{l}\text { Overweight } \\
(n=45)\end{array}$ & $\begin{array}{l}\text { Obese } \\
(n=29)\end{array}$ \\
\hline \multicolumn{5}{|l|}{ Children } \\
\hline Age, mean $\pm S D$ & $7.3 \pm 0.82$ & $7.4 \pm 0.94$ & $7.3 \pm 0.92$ & $7.5 \pm 0.95$ \\
\hline Sex, female, \% & 14.3 & 48.8 & 48.9 & 48.3 \\
\hline HFA z-score, mean \pm SD & $-0.12 \pm 0.69$ & $0.26 \pm 0.91$ & $0.99 \pm 0.91$ & $1.12 \pm 1.01$ \\
\hline BMI z-score, mean $\pm S D$ & $-2.55 \pm 0.51$ & $-0.39 \pm 0.71$ & $1.39 \pm 0.32$ & $2.90 \pm 0.84$ \\
\hline \multicolumn{5}{|l|}{ Caregiver } \\
\hline Age, mean $\pm S D$ & $35.6 \pm 10.4$ & $34.5 \pm 9.5$ & $34.8 \pm 9.1$ & $39.6 \pm 10.4$ \\
\hline Sex, female, \% & 93.3 & 95.4 & 98.7 & 96.6 \\
\hline Unmarried, \% & 57.1 & 46.2 & 57.6 & 69.2 \\
\hline $\mathrm{BMI}$, mean $\pm \mathrm{SD}$ & $36.9 \pm 6.9$ & $40.1 \pm 9.5$ & $40.1 \pm 8.3$ & $41.9 \pm 6.9$ \\
\hline \multicolumn{5}{|l|}{ Country, } \\
\hline Trinidad \% & 86.0 & 52.4 & 57.8 & 58.6 \\
\hline \multicolumn{5}{|l|}{ Education } \\
\hline$<$ secondary, \% & 43.8 & 43.8 & 52.5 & 35.3 \\
\hline
\end{tabular}

$S D$ standard deviation

18 months of follow-up. For each additional unit of baseline BMI z-score, the BMI increased by $0.43 \mathrm{BMI}$ units (adjusted for age and sex), indicating that the heaviest children at baseline gained the most weight. This analysis was adjusted for energy intake, and the misreporting of energy intake as well as caregiver BMI but none of these variables were associated with increasing BMI over time. Misreporting of energy intake was evaluated to verify the validity of the dietary data. More under-reporting was found among overweight and obese children when compared to those children who were not overweight or obese ( $27 \%$ vs. $17 \%, p=0.047)$; hence, we adjusted for misreporting in our regression model. The model is presented in Table 5 .

\section{Discussion}

In the present study we investigated the development of overweight and obesity among school-aged children in the Caribbean over 18 months and predictors of increasing BMI over time. There were important increases in overweight and obesity over the study period with $15 \%$ becoming overweight or obese vs. less than $2 \%$ of overweight/

Table 2 Children's weight status at baseline and follow-up in two Caribbean countries, St. Kitts and Nevis and Trinidad and Tobago $(n=336)$

\begin{tabular}{llllll}
\hline & Thin & Healthy weight & Overweight & Obese & $p$ \\
\hline Baseline & $14(4.2)$ & $248(73.8)$ & $45(13.4)$ & $29(8.6)$ & $<0.001$ \\
Follow-up & $15(4.5)$ & $225(67.0)$ & $44(13.1)$ & $52(15.5)$ & \\
\hline
\end{tabular}

Chi-square test was preformed

Absolute values $(n)$ are provided in the table; values in parenthesis represent percentages obese children getting into a healthier weight category. There were no differences in dietary intake among children in different weight categories at baseline, except a lower consumption of fruit was evident in those who increased a weight category. The major predictor of gains in BMI was the baseline BMI z-score, indicating that heavier children are those most likely to become even heavier.

The rapid increase in the prevalence of overweight and obesity among our sample of children was reflected by the mean change in BMI (adjusted for age and sex), which was $1.3 \mathrm{~kg} / \mathrm{m}^{2}$. This increase above the WHO standard for growth at this age was less than observed in children aged $8-10$ years in Québec $\left(1.7 \mathrm{~kg} / \mathrm{m}^{2}\right)$. Both studies investigated changes in adiposity among children whose parents were overweight or obese [34]. Lower mean weight gains among children in our sample could be due to the fact that children in the Quebec study had a higher baseline level of overweight and the sample was slightly older. In this study, $9 \%$ of children increased their weight categories to become overweight and 8.1\% became obese over the study period. These values are high when compared to findings from an Australian cohort study conducted over 3 years $(1997-2000)$ with children aged $5-10$ years at baseline $(n=1438)$; in that study, the incidence of overweight was similar (9.7\%) but that for obesity was much lower (1.7\%) [35].

Increased prevalence of overweight and obesity indicate an imbalance of EI and physical activity at the population level [14]. In this study, energy intake was similar across all weight categories. In fact, total energy expenditure was not investigated, but it was evident that overweight and obese children under-reported their energy intake compared to 
Table 3 Baseline dietary intake by change in weight category of school-aged children 6-12 years from two Caribbean countries, St. Kitts and Nevis and Trinidad and Tobago $(n=296)^{*}$

\begin{tabular}{llll}
\hline & $\begin{array}{l}\text { Children who did not move up } \\
\text { a weight category }(n=252)\end{array}$ & $\begin{array}{l}\text { Children who became overweight } \\
\text { or obese }(n=44)\end{array}$ & $1781 \pm 536$ \\
\hline Energy, kcal & $1825 \pm 547$ & $263 \pm 99.0$ & 0.628 \\
Carbohydrate, g & $275 \pm 96.2$ & $62.6 \pm 21.4$ & 0.447 \\
Protein, g & $59.0 \pm 26.3$ & $57.4 \pm 23.9$ & 0.269 \\
Fat, g & $57.1 \pm 26.7$ & $104 \pm 61.0$ & 0.813 \\
Total sugar, g & $113 \pm 59.4$ & $14.2 \pm 7.40$ & 0.283 \\
Fiber, g & $14.2 \pm 7.58$ & $612 \pm 323$ & 0.998 \\
Calcium, mg & $608 \pm 328$ & $14.1 \pm 9.50$ & 0.924 \\
Iron, mg & $13.7 \pm 9.40$ & $7.25 \pm 3.99$ & 0.984 \\
Staple, portions & $8.23 \pm 5.43$ & $4.57 \pm 3.13$ & 0.358 \\
Foods from animals, portions & $3.97 \pm 3.43$ & $0.14 \pm 0.40$ & 0.202 \\
Legumes and nuts, portions & $0.19 \pm 0.56$ & $0.54 \pm 0.92$ & 0.633 \\
Fruits, portions & $0.98 \pm 1.66$ & $1.19 \pm 1.30$ & 0.017 \\
Vegetables, portions & $1.10 \pm 1.67$ & & 0.206 \\
\hline
\end{tabular}

*Thin children and children who were obese at baseline were excluded

Values presented are means \pm standard deviations

children who were normal weight. Misreporting of dietary intake data is a major challenge in gaining a better understanding of the foods actually consumed. Adjusting for the misreporting of energy intake when analyzing the data in order to establish more accurate epidemiological relationships is suggested [36], but the problem of knowing which foods are misreported remains a challenge and may lead to failing to pick up some types of foods that increase the risk of excessive weight gain.

Dietary intakes were similar among children from all weight categories and children who become overweight or obese versus children who did not; only fruit intake was lower among children who moved up weight category compared to children who did not. The relationship between fruit and/or vegetable intake and weight gain is evident among adults but among children the findings have been inconsistent, with some but not all showing a protective effect of fruits and vegetables [37].

In this study, children with higher weight at baseline gained the most weight over 18 months of follow-up and this is in line with findings of other studies. It has been reported in North America that heavier children are gaining weight more quickly than children with healthy weight children $[15,38]$ and reports indicate that approximately $50 \%$ of obese school-aged children will become obese adults [5]. In this study, height and age were also strong predictors for increased adiposity and that is in line with previous findings $[39,40]$.

Previous research has identified a positive association between parental BMI and children's weight status [16, 17]. In this study, however, $97 \%$ of the caregivers were identified as overweight or obese, in the Caribbean young women have a higher prevalence of obesity than men [41]. The sex of the child was not a concern in this study as weight gain peaks for both girls and boys after the age of 12 years (for girls 12.5 years and for boys 14 years) [42, 43], and no sex difference is evident before this age.

The major strengths of this study include its longitudinal design, which allowed us to measure the change in BMI among children ages 6-10 years and not just examine secular changes over time. In addition, misreporting of energy intake was assessed in our study and controlled for in the regression analysis. Energy intake alone should not be used to measure energy balance unless misreporting is accounted for. However, some limitations of this study should also be considered. Our sample is not representative of the general

Table 4 Change in BMI among children by baseline quartiles of BMI Z-score in two Caribbean countries, St. Kitts and Nevis and Trinidad and Tobago $(n=336)$

\begin{tabular}{llllll}
\hline & 1st quartile & 2nd quartile & 3rd quartile & 4th quartile & $p$ \\
\hline Number of children & 83 & 85 & 85 & 83 & $<0.001$ \\
Change in BMl (adjusted & ) & $0.68 \pm 1.3^{\mathrm{a}}$ & $1.1 \pm 1.1^{\mathrm{b}}$ & $1.2 \pm 1.5^{\mathrm{c}}$ & $2.5 \pm 1.6^{\mathrm{d}}$ \\
\hline
\end{tabular}

Numbers are means \pm standard deviations

*Adjustment for age was done by subtracting the sex-age-specific median BMI

$a, b, c, d$ different superscripts indicate statistically different means 
Table 5 Multiple regression model of association with change in children's BMI* from two Caribbean countries, St. Kitts and Nevis and Trinidad and Tobago $(n=336)$

\begin{tabular}{llll}
\hline & Beta estimate & SE & $p$ \\
\hline Age, years & 0.19 & 0.08 & 0.019 \\
Baseline BMI z-score & 0.43 & 0.06 & $<0.001$ \\
Baseline HFA z-score & 0.21 & 0.08 & 0.007 \\
Energy intake, baseline, 100 kcal & -0.03 & 0.01 & 0.057 \\
Misreporting of energy intake & 0.16 & 0.24 & 0.499 \\
Caregiver BMl & 0.01 & 0.01 & 0.183 \\
R-square & 0.23 & & \\
\hline SE & & &
\end{tabular}

SE standard error

*Adjustment for age was done by subtracting the sex-age-specific median BMI

population in the Caribbean because the schools in Trinidad were chosen based on their having a high proportion of children from families considered to be "in need". Also, reliable measures of physical activity were not available so that one cannot know if the important weight gains in the heavier children were due to lower levels of physical activity in the heavier children.

\section{Conclusions}

The prevalence of overweight and obesity is known to be a rapidly growing problem among children in the Caribbean. Predictors of excessive weight gain in individual primary school children clearly show that the heaviest children gain the most excess weight over a relatively short period of time, thereby adding to their health burden. Interventions early in a child's life to lessen the risk of becoming overweight and to help overweight and obese children to not continue to gain excessive weight are important to reduce noncommunicable diseases in the future.

\section{Abbreviations}

BMI: Body Mass Index; CARICOM: Caribbean Community and Common Market; El: Reported energy intake; HFA: Height-for-age; SD: Standard deviation; TEE: Total energy expenditure; USDA: United States Department of Agriculture; WHO: World Health Organization

\section{Acknowledgments \\ Thanks are due to Louise Johnson-Down for her contribution to the dietary data collection and overall data management. We wish to acknowledge the collaboration and support from the St. Kitts and Nevis Ministry of Education and Information, and Ministry of Health and Social Services, and the dedication of the local staff attached to the project, who collectively made the study possible.}

\section{Funding}

This work was carried out with the aid of a grant from the International Development Research Centre (IDRC), Ottawa, Canada, https://www.idrc.ca/, and with financial support from the Government of Canada, provided through Global Affairs Canada (GAC). Project number 106525.

\section{Availability of data and materials}

The datasets used and/or analyzed during the current study are available from the corresponding author on reasonable request.

\section{Authors' contributions}

WAM analyzed data, wrote the paper and had primary responsibility for final content. IFG designed the research, oversaw data collection, revised manuscript and approved final version. LEP designed the research, oversaw data collection, revised the manuscript and approved final version. KGD designed the research, oversaw data collection and critically revised the manuscript and approved final version. All authors read and approved the final manuscript.

\section{Ethics approval and consent to participate}

Ethical approvals were obtained from the McGill Research Ethics Committee, the Ministry of Education in St. Kitts and Nevis, the Ministry of Health St. Kitts and Nevis, the Ministry of Food Production, Land and Marine Affairs in Trinidad and Tobaggo, the Ministry of Health and the Ministry of Education, Republic of Trinidad and Tobago, Research and Publication Unit. A letter to parents requesting the participation of caregiver and their child was provided to the household and only those children with signed parental consent were enrolled in the study.

\section{Consent for publication}

Not applicable.

\section{Competing interests}

The authors declare that they have no competing interests.

\section{Publisher's Note}

Springer Nature remains neutral with regard to jurisdictional claims in published maps and institutional affiliations.

\section{Author details}

${ }^{1}$ Clinical Nutrition Department, College of Applied Medical Sciences, Taibah University, Al-Madinah, Saudi Arabia. ${ }^{2}$ Faculty of Food and Agriculture, University of the West Indies, St. Augustine Campus, Trinidad and Tobago. ${ }^{3}$ Department of Animal Science, McGill University 21, 111 Lakeshore Road, Sainte-Anne-de-Bellevue, Québec H9X 3V9, Canada. ${ }^{4}$ School of Dietetics and Human Nutrition, McGill University 21, 111 Lakeshore Road,

Sainte-Anne-de-Bellevue, Québec H9X 3V9, Canada.

Received: 10 July 2017 Accepted: 19 January 2018

Published online: 30 January 2018

\section{References}

1. Nguyen DM, El-Serag HB. The epidemiology of obesity. Gastroenterol Clin N Am. 2010; https://doi.org/10.1016/j.gtc.2009.12.014.

2. Ng M, Fleming T, Robinson M, Thomson B, Graetz N, Margono C, et al. Global, regional, and national prevalence of overweight and obesity in children and adults during 1980-2013: a systematic analysis for the global burden of disease study 2013. Lancet. 2013; https://doi.org/10.1016/S0140-6736(14)60460-8.

3. Guo SS, Chumlea WC. Tracking of body mass index in children in relation to overweight in adulthood. Am J Clin Nutr. 1999;70(1):145s-8s.

4. Freedman DS, Khan LK, Dietz WH, Srinivasan SR, Berenson GS. Relationship of childhood obesity to coronary heart disease risk factors in adulthood: the Bogalusa heart study. Pediatrics. 2001;108(3):712-8.

5. Serdula MK, Ivery D, Coates RJ, Freedman DS, Williamson DF, Byers T. Do obese children cecome cbese adults? A review of the literature. Prev Med. 1993; https://doi.org/10.1006/pmed.1993.1014

6. Lambert M, Delvin EE, Levy E, O'Loughlin J, Paradis G, Barnett $T$, et al. Prevalence of cardiometabolic risk factors by weight status in a population-based sample of Quebec children and adolescents. Can J Cardiol. 2008;24(7):575-83.

7. Romualdo MC, Nóbrega FJ, Escrivão MA. Insulin resistance in obese children and adolescents. J Pediatr. 2014;90(6):600-7.

8. Shalitin S, Abrahami M, Lilos P, Phillip M. Insulin resistance and impaired glucose tolerance in obese children and adolescents referred to a tertiarycare center in Israel. Int J Obes. 2005;29(6):571-8.

9. Sorof J, Daniels S. Obesity hypertension in children: a problem of epidemic proportions. Hypertension. 2002;40(4):441-7.

10. Hebestreit A, Börnhorst C, Barba G, Siani A, Huybrechts I, Tognon G, et al. Associations between energy intake, daily food intake and energy density of foods and BMI z-score in 2-9-year-old European children. Eur J Nutr. 2014;53(2):673-81. 
11. Stice E, Durant $\mathrm{S}$. Elevated objectively measured but not self-reported energy intake predicts future weight gain in adolescents. Appetite. 2014;81:84-8.

12. Shang L, O'Loughlin J, Tremblay A, Gray-Donald K. The association between food patterns and adiposity among Canadian children at risk of overweight. Appl Physiol Nutr Metab. 2014;39(2):195-201.

13. Receveur O, Morou K, Gray-Donald K, Macaulay AC. Consumption of key food items is associated with excess weight among elementary-schoolaged children in a Canadian first nations community. J Am Diet Assoc. 2008;108(2):362-6.

14. Hill JO, Wyatt HR, Peters JC. Energy balance and obesity. Circulation. 2012; 126(1):126-32

15. O'Loughlin J, Gray-Donald K, Paradis G, Meshefedjian G. One- and two-year predictors of excess weight gain among elementary schoolchildren in multiethnic, low-income, inner-city neighborhoods. Am J Epidemiol. 2000; 152(8):739-46.

16. Wrotniak BH, Epstein LH, Paluch RA, Roemmich JN. Parent weight change as a predictor of child weight change in family-based behavioral obesity treatment. Arch Pediatr Adolesc Med. 2004;158(4):342-7.

17. Parikka S, Mäki $P$, Levälahti E, Lehtinen-Jacks S, Martelin T, Laatikainen T. Associations between parental BMl, socioeconomic factors, family structure and overweight in Finnish children: a path model approach. BMC Public Health. 2015; https://doi.org/10.1186/s12889-015-1548-1.

18. Popkin BM, Adair LS, Ng SW. Global nutrition transition and the pandemic of obesity in developing countries. Nutr Rev. 2012;70(1):3-21.

19. Amuna P, Zotor FB. Epidemiological and nutrition transition in developing countries: impact on human health and development. Proc Nutr Soc. 2008; 67(1):82-90.

20. Xuereb G, Bocage C, Marris A, Johnson P. Obesity in Caribbean children: its magnitude and current control efforts. Caribbean Food Nutr Inst. 2001;34(3):120-6.

21. Fernandez MA, Kubow S, Gray-Donald K, Knight J, Gaskin PS. Drastic increases in overweight and obesity from 1981 to 2010 and related risk factors: results from the Barbados children's health and nutrition study. Public Health Nutr. 2015;18(7):3070-7.

22. Phillip LE, Francis-Granderson I. Improving the nutrition and health of CARICOM populations:final technical report (march 2011-august 2014): International Development Research Center. https://idl-bnc-idrc dspacedirect.org/handle/10625/53596. Accessed 13 Jan 2016; 2014.

23. Eck $L H$, Klesges $R C$, Hanson $C L$. Recall of a child's intake from one meal: are parents accurate? J Am Diet Assoc. 1989;89:784-7.

24. World Health Organization. BMl-for-age (5-19 years), in growth reference 519 years. World Health Organization; 2013. http://www.who.int/growthref/ who2007_bmi for_age/en/. Accessed 20 May 2016

25. Cole TJ, Faith MS, Pietrobelli A, Heo M. What is the best measure of adiposity change in growing children: $\mathrm{BMI}, \mathrm{BMI} \%, \mathrm{BMI}$ z-score or BMI centile. Eur J Clin Nutr. 2005;59(3):419-25.

26. World Health Organization. Growth reference 5-19 years, height-for-age (519 years): World Health Organization; 2015. http://www.who.int/growthref/ who2007_height_for_age/en/. Accessed 20 May 2016

27. Health Canada. Food and nutrition, the Canadian nutrient file: Health Canada; 2007. http://www.hc-sc.gc.ca/fn-an/nutrition/fiche-nutri-data/user_ guide_d_utilisation01-eng.php. Accessed 26 Jan 2016

28. Zephirin PM. Manual of nutrition and dietetic practice for the Caribbean 3rd ed. Kingston: Caribbean Food and Nutrition Institute; 1990.

29. Health Canada. Food and nutrition, what is a food guide serving? Health Canada. 2007. http://www.hc-sc.gc.ca/fn-an/food-guide-aliment/basics-base/ serving-portion-eng.php. Accessed 26 Jan 2016.

30. Beaton $\mathrm{GH}$, Milner J, McGuire V, Feather TE, Little JA. Sources of variance in 24-hour dietary recall data: implications for nutrition study design and interpretation. Carbohydrate sources, vitamins, and minerals. Am J Clin Nutr. 1983;37(6):986-95.

31. Torun B. Energy requirements of children and adolescents. Public Health Nutr. 2005:8(7A):968-93.

32. Black AE. The sensitivity and specificity of the Goldberg cut-off for El: BMR for identifying diet reports of poor validity. Eur J Clin Nutr. 2000; 54(5):395-404

33. World Health Organization. BMI classification: World Health Organization 2015. http://www.who.int/mediacentre/factsheets/fs311/en/. Accessed 13 Jan 2016

34. Kakinami L, Henderson M, Chiolero A, Cole TJ, Paradis G. Identifying the best body mass index metric to assess adiposity change in children. Arch Dis Child. 2014;99(11):1020-4.
35. Hesketh K, Wake M, Waters E, Carlin J, Crawford D. Stability of body mass xindex in Australian children: a prospective cohort study across the middle childhood years. Public Health Nutr. 2004;7(2):303-9.

36. Subar AF, Freedman LS, Tooze JA, Kirkpatrick SI, Boushey C, Neuhouser ML, et al. Addressing current criticism regarding the value of self-report dietary data. J Nutr. 2015;145(12):2639-45.

37. Ledoux TA, Hingle MD, Baranowski T. Relationship of fruit and vegetable intake with adiposity: a systematic review. Obes Rev. 2011;12(5):e143-50.

38. Butte NF, Cai G, Cole SA, Wilson TA, Fisher JO, Zakeri IF, et al. Metabolic and behavioral predictors of weight gain in Hispanic children: the viva la Familia study. Am J Clin Nutr. 2007;85(6):1478-85.

39. Frye $C$, Heinrich J. Trends and predictors of overweight and obesity in east German children. Int J Obes Relat Metab Disord. 2003;27(8):963-9.

40. Freedman DS, Khan LK, Mei Z, Dietz WH, Srinivasan SR, Berenson GS. Relation of childhood height to obesity among adults: the Bogalusa heart study. Pediatrics. 2002;109(2):E23.

41. Caribbean Food and Nutrition Institute. The contribution of CFNI to Caribbean development 2001-2010. Kingston: Caribbean Food and Nutrition Institute; 2010

42. Barnes HV. Physical growth and development during puberty. Med Clin North Am. 1975;59(6):1305-17.

43. Tanner JM. The relationship of puberty to other maturity indicators and body composition in man. In Symp Soc Stud Hum Biol. 1965;6:211.

\section{Submit your next manuscript to BioMed Central and we will help you at every step:}

- We accept pre-submission inquiries

- Our selector tool helps you to find the most relevant journal

- We provide round the clock customer support

- Convenient online submission

- Thorough peer review

- Inclusion in PubMed and all major indexing services

- Maximum visibility for your research

Submit your manuscript at www.biomedcentral.com/submit 